\title{
MUSIC AND EMOTIONS
}

\author{
Dr.Sushma Sharma \\ Assistant Professor, Govt. College, Sector 46, Chandigarh
}

Music is a composition of melodic sounds which please human mind. It has been said that sound is the background of music. A sound is a composite of body of vibration of either unit, surcharged with energy. All the musicologists have said that sound is divided into two parts, unconscious unmanifested (anahata) and conscious manifested (ahata) ones. The manifested sound represented itself as the non-musical sound like speech and the musical sound like song. The musical sound is melodious, sweet and soothing, where as non- musical sound is suitable only for speech.

Since music is an expression of human life which is endless and exists everywhere, therefore music is also exists everywhere. Our cultural, social, political, econimal and scientifically levels depict in music. All the 9 rasas - Shringar, Shanta, Karuna, Veer, Radura, Adbhuta, Bhayanak, Hasya and Bhakti can be expressed through music. A song without any music cannot be so powerful in effect as it can be with music. A musical song can very easily induce that desired Rasas and produce joy and sorrow.

The observation that musical appreciation apparently arises spontaneously in children offers evidence in favour of an inate tendency. The effect of music has been documented in the variety of studies, ranging from neurologically and psychological correlation to the use of music as therapy as relaxation, in enhancing physical performance, in creating an attention or respective mood in connection with advertising and interaction.

Sound is the most powerful medium to express emotions. A psycho- analyst says that speech is in fact a system of emotional and intuitive sounds which expresses terror, fear, anger, love, sympathy etc. In music the emotions are expressed through the medium of various tones i.e. sound. In dance these are expressed by various actions of the hands, feet, eyes facial countenance etc. Music really is the emotional presentation of sounds or succession of sounds or tones - an emotional symbolism of man's inner depth. When the colourful tones are presented, both the musicians and the listeners cannot but help expressing their mental attitude outwardly by the movements of head and limbs, a rag is an emotional product or emotive manifestation of mental attitudes and so it expresses the aesthetic feeling of love devotion anger egoism etc.

\section{Emotional Expressions}

An emotion, as it is commonly known is a distinct feeling or quality of consciousness, such as joy or sadness that affects the personal significance of an emotion - arousing event. In modern time the subject of emotion has become part of the subject matter of several scientific disciplines' - biology, psychology, psychiatry, anthropology and Sociology. Emotions are central to the issues of human survival and adaptation. They motivate the development of moral behaviour, which lies at the very rout of civilization. 
Emotion influence empathic and altruistic behaviour and they play a role in the creative processes of the mind. They affect the basic processes and perception and influence the way humans conceive and interpret the world around them. Evidence suggests that emotions shape many other aspects of human life and human affairs. Emotions generally has a pleasant -unpleasant dimension, and organisms tend to continue giving responses related to pleasure and to stop or avoid those related to unpleasantness or pain.

\section{Expression of emotion through music}

At its broadest, music can be regarded as a medium for expressing thoughts and feeling through tones and times. The basic elements of music that combine to achieve this affect our melody, rhythm and harmony. Their combinations give rise to musical forms. Music is a mode of thinking in tone and rhythms. Hearing of simple music stimulates different types of awareness. Thus music convey although the tones except in the physical sense, incapable of definition as the substance of the tones hardly forms the vehicle of thought. This is especially true of primitive music. We have to discover fundamental principle by which certain organisation of sounds makes sense.

If there is anything in the world that can give expression to the mind and the feelings, it is the voice. Often it happens that a person talks on a subject with a thousand words, and it has no influence. Another person expresses a thought in three words and makes a deep impression. This shows that power is not in the world but in what is behind the world that is the psychological power in the voice which comes from prana. According to the strength it has, it impresses the listener.

Indian music expresses the pleasure and sorrow of love, the devout feeling of a bhakta towards god, the tender love of mother to her child. It can well express all personal feelings which the heart is capable of giving expression to. Of all fine arts, music is the most intimate and fullest expression of human nature. Sound and rhythm are the two constituents of music which instinctively attract almost everybody.

Music is a unique way of expressing feeling and thoughts. It is due to its incorporation with the assimilation of different aspects of tempo, lay and metre, the tonal structure of rag waves around a hallucinating environment in which the artist express his feelings in a very methodological and effective manner. Music is capable is expressing emotions. Though there are some factors which are of great importance for inducing the emotive values. These factors are as follows- musical composition, form of music, rhythm, acoustics of music, verities of instruments, personal preference and receptiveness, efficiency of the performer, cultural background and various ragas.

\section{Emotional effects of music}

It is quite a very hard task to study the effect of music on listener as well as on performer. It is only a music psychologist, who studies the arousal of emotion in a listener after listening to music. This is the matter to study that how our brain reacts to 
music. Even a layman responds emotionally to music just like a music performer. Various feeling are infect experienced during listening and performing music.

For a raga to colour the mind o a listener in the true sense, its effect must be created not only through the notes and the embellishments, but also through the presentation of a specific emotion of each ragas. Through the rich melodies of our music, every human emotion, every suitable mood in human mind and in nature can be expressed.

\section{Effect of music on emotional and behavioural problems}

Among the psychological effects of music, the most pronounced ones are in the behaviour and temperament of the individuals. Emotions, feelings and thoughts have been reported to be greatly influenced by music listening and participation in music making. Emotional experience derived from music has a powerful effect on the formation of one's moral and intellectual outlook. Music activities lead to the development of imagination and creative thinking. Singing playing a musical instrument and rhythmic movements provide better sense of proportion, a finer, perception and a happier world outlook. Shyness aggressiveness and many other such characters of individuals have been normalising by music.

Music is absolutely concerned with the problems of emotional content, value and beauty. It is one of the most wonderful arts in the hands of mankind to alter or modify the feelings and emotions. In all living beings to such an extent that it works better than any form of therapy in the world. It is the easiest, cheapest and simplest form of therapy for the correction of many ills and suffering of the living creature of this world. A song or few chords on piano or playing any instrument will very quickly change the atmosphere. The effect is on both the performer and the listener.

\section{References}

Swami Prajnananada- A Historical study of Indian music. Munshirm Manoharlal Pub Pvt Ltd.

S.M. Tagore- Universal history of music. Sanjay Prakashan, Delhi, 2005

Ravi Shankar- My music my life. Mandala Publishers

Manorama Sharma- Special education-Music therapy. Publisher- Nataraj Books (June 1996), Encyclopaedia of Psychology, Vol.1. Kazdin, Alan E(ed) ,New York NY.US Oxford University press

The New Encyclopaedia Britannica.Vol.18. 